\title{
POLÍTICA DE EXPANSÃO DA EDUCAC̣̃̃O SUPERIOR NO BRASIL - O PROUNI E O FIES COMO FINANCIADORES DO SETOR PRIVADO
}

\author{
Vera Lúcia Jacob Chaves* \\ Universidade Federal do Pará (UFPA), Belém - PA, Brasil \\ Nelson Cardoso Amaral" \\ Universidade Federal de Goiás (UFG), Goiânia - G0, Brasil
}

RESUMO: O estudo analisa a política de expansão da educação superior brasileira no período 2003-2014, tendo como ênfase a análise do Programa Universidade para Todos (ProUni) e do Programa de Financiamento Estudantil (FIES) como financiadores do setor privado. Utilizou-se como recurso metodológico a pesquisa quanti-qualitativa, com consulta a fontes documentais e aos websites da Receita Federal do Brasil e do Senado Federal, para o levantamento de dados financeiros, e do Censo da Educação Superior, para obtenção daqueles referentes a matrículas e instituições de educação superior. O estudo evidenciou que uma política de expansão ocorreu tanto para o setor público quanto para o privado, e que este último recebeu substanciais incentivos governamentais, especialmente pelas vias do ProUni e do FIES, o que tem contribuído para a obtenção de lucro e a oferta de uma educação superior que dissocia o ensino de graduação da pesquisa e da extensão.

Palavras-chave: Expansão privada. Financiamento. ProUni. FIES.

\section{EXPANSION POLICY FOR HIGHER EDUCATION IN BRAZIL - PROUNI AND FIES AS PRIVATE SECTOR FINANCERS}

ABSTRACT: The study analyzes the expansion policy for Brazilian higher education in the period 2003 through 2014, emphasizing the analysis of ProUni and FIES as private sector financers. The methodological resources encompassed both quantitative and qualitative research procedures, consulting documental sources and the websites of the Department of

http://dx.doi.org/10.1590/0102-4698162030

"Doutora em Educação pela Universidade Federal de Minas Gerais (UFMG). Professora Pesquisadora e Vice-Coordenadora do Programa de Pós-Graduação em Educação da Universidade Federal do Pará (UFPA). Integrante da Rede Universitas/Br. E-mail: < veraluciajacob@gmail.com>.

“* Doutor em Educação pela Universidade Metodista de Piracicaba (UNIMEP). Professor Pesquisador do Programa de Pós-Graduação em Educação da Universidade Federal de Goiás (UFG). Integrante da Rede Universitas/Br. E-mail: < nelsoncardosoamaral@gmail.com>. 
Federal Revenue of Brazil and the Federal Senate to gather general financial data, and the website of the Higher Education Census to gather financial data about enrollments and higher education institutions. The study has evidenced that an expansion policy occurred for both private and public sectors, and that the private sector received substantial support from the Government, especially through the ProUni and FIES programs, which has contributed to the achievement of profit, while providing a higher education model that dissociates undergraduate education from research and extension activities.

Keywords: Private expansion. Financing. ProUni. FIES.

\section{INTRODUCุÃO}

A expansão da educação superior brasileira vem sendo pautada pelos governos brasileiros desde a ditadura militar, estando presente nas políticas públicas federais definidas para esse nível. As informações contidas nos Censos da Educação Superior, publicados, anualmente, pelo Instituto Nacional de Estudos e Pesquisas Educacionais Anísio Teixeira (INEP), mostram que, mesmo existindo períodos de grande expansão do setor público, a predominância é da ampliação de instituições e matrículas no setor privado.

O estudo ora relatado teve como objetivo central analisar a política de expansão da educação superior brasileira no período que se estende de 1995 a 2014, tendo como ênfase a análise do Programa Universidade para Todos (ProUni), implantado pela Lei no 11.096, de 13 de janeiro de 2005, e do Fundo de Financiamento Estudantil (FIES), programa estabelecido, em 12 de julho de 2001, pela Lei ${ }^{\circ}$ 10.260, como fontes de financiamento para o setor privado.

No desenvolvimento da pesquisa, buscou-se responder às seguintes questões: Qual a relação entre a política de incentivos fiscais, por meio do ProUni e do financiamento estudantil na expansão do Ensino Superior privado, e o montante da renúncia tributária presente nesse programa? Qual o mecanismo envolvido nos recursos do FIES, que não paga as escolas com dinheiro, mas sim com títulos do Tesouro Nacional, e quais os recursos financeiros totais desse Fundo? O que representam os recursos financeiros presentes nesses dois programas em relação ao orçamento executado pela União, na função educação?

Utilizou-se, como recurso metodológico, a pesquisa quantiqualitativa, com consulta a fontes documentais e aos websites da Receita Federal do Brasil e do Senado Federal, para o levantamento de dados financeiros, e do Censo da Educação Superior, referentes às informações sobre matrículas e instituições de educação superior 
(IES) no período de 1995 a 2014, que abrange os governos de Fernando Henrique Cardoso - governo FHC (1995-2002) -, de Luiz Inácio Lula da Silva - governo LULA (2003-2010) - e Dilma Rousseff - governo DILMA, no período 2011-2014.

O texto se estrutura em três partes. Na primeira, apresentamos uma breve reflexão sobre a política de privatização da educação superior no contexto de crise do capital e a adoção do neoliberalismo e do ajuste fiscal na definição das políticas sociais, com repercussão na educação. Na segunda parte, analisamos a política de expansão da educação superior brasileira e o movimento da relação entre o público e o privado no período demarcado para estudo, com base nos dados coletados nos Censos da Educação Superior publicados pelo INEP para tal período. Na terceira parte do texto, apresentamos algumas respostas para as questões anteriormente enunciadas, para, depois, tecer as considerações finais.

\section{A POLÍTICA DE PRIVATIZAC̣ÃO DA EDUCAC̣ÃO SUPERIOR BRASILEIRA NO CONTEXTO DE CRISE DO CAPITAL}

O projeto de educação dos organismos multilaterais, como o Banco Mundial (BM), o Fundo Monetário Internacional (FMI) e a Organização para a Cooperação e Desenvolvimento Econômico (OCDE), para os países periféricos do capital é caracterizado pelo aprofundamento da privatização, pela desnacionalização da educação, pela consolidação de um novo mercado educativo global, o que o caracteriza como sendo de cunho neoliberal. Tal projeto, explicitado claramente pelo BM (BANCO MUNDIAL, 1995), vem sendo materializado por uma série de reformas educativas na América Latina, induzidas por meio de acordos estabelecidos entre esses organismos e os governos, e que possuem, entre suas finalidades, imergir a educação no mundo capitalista, que possui como prioridade a obtenção de lucratividade financeira. É importante ressaltar que, apesar da educação superior privada ter sido expandida no Brasil com a reforma universitária de 1968, as políticas gestadas no Consenso de Washington ${ }^{1}$ direcionaram reformas que deveriam ser implementadas com a finalidade de ampliar o mercado para setores da sociedade a serem explorados, na busca de rentabilidade.

As reformas seriam adotadas como medidas para superação da crise estrutural que o sistema vivenciava, desde os anos finais de 1970, quando iniciou-se uma nova etapa do processo de acumulação 
capitalista marcada pela ascensão do capital financeiro, como destaca Chesnais (1996, p. 19): “[...] o estilo de acumulação é dado pelas novas formas de centralização de gigantescos capitais financeiros (os fundos mútuos e fundos de pensão) cuja função é frutificar principalmente no interior da esfera financeira".

As transformações ocorridas no mercado financeiro mundial de liberação e desregulamentação dos fluxos financeiros, da interligação dos mercados, da criação de inovações financeiras (derivativos, securitização, contratos futuros etc.) e de fundos de investimentos institucionais, são denominadas por estudiosos de financeirização ${ }^{2}$.

O Brasil se insere nesse "circuito internacional de valorização financeira" desde o governo Itamar Franco (1992-1993), "com a desregulamentação do mercado financeiro brasileiro e a abertura do fluxo internacional de capitais" (PAULANI, 2008, p. 90). Para tanto, foram adotadas ações que viabilizassem tal política econômica, como o Plano Real. Paulani (2008, p. 91) esclarece esse processo como segue:

O lançamento de títulos de dívida brasileira cotados no exterior confirmou o país no papel de emissor de capital fictício ${ }^{3}$, que viabiliza a valorização financeira e garante a posteriori a transferência de parcelas da renda real e do capital real para essa esfera de acumulação. A liberalização financeira vem garantir o livre trânsito dos capitais internacionais [...]. A abertura da economia, as privatizações, a manutenção da sobrevalorização da moeda brasileira, a elevação inédita da taxa real de juros, tudo passou a ser justificado pela necessidade de preservar a estabilidade monetária conquistada pelo Plano Real.

É nesse contexto de adequação do país para sua inclusão no mercado financeiro internacional que se insere, também, a Lei de Responsabilidade Fiscal - LRF - (Lei Complementar no 101, de maio de 2000), elaborada no governo FHC (BRASIL, 2000). Essa lei impõe uma série de restrições à utilização do fundo público para os gastos sociais visando a preservar o superávit primário ${ }^{4}$ e garantir aos credores internacionais o pagamento dos serviços da dívida pública brasileira.

Os governos do Partido dos Trabalhadores mantiveram, no período em análise, a mesma política econômica de valorização financeira internacional, contrariando a expectativa de que seria reduzido o grau de submissão ao capital rentista nacional e internacional. Para tanto, adotaram medidas ortodoxas na economia como a elevação das taxas de juros e mudanças no câmbio, de forma a facilitar a remessa de recursos ao exterior. Em relação às políticas sociais, aprofundaram a privatização dos serviços públicos por meio das Parcerias Público-Privadas (PPP) ${ }^{5}$, transferindo a responsabilidade do Estado para o setor privado. Por outro lado, adotaram medidas compensatórias para atender a população 
que se encontrava em "situação de risco". Assim, as políticas sociais transformam-se em sinônimo de política social focalizada, direcionadas aos mais pobres, pela via da adoção de programas de complementação de renda, como o Programa Bolsa Família.

Em 2008, a crise do sistema financeiro do capital se aprofundou com a explosão da bolha habitacional, nos Estados Unidos, atingindo todo o sistema mundial de finanças (COGGIOLA, 2011). Essa crise foi agravada pela hipertrofia desse setor na economia capitalista, com a destruição de trilhões de dólares de ativos financeiros, causando perdas imensas às famílias estadunidenses e, logo em seguida, afetando vários países do centro do capital, como revela Harvey (2011, p. 13):

No fim de 2008, todos os segmentos da economia dos EUA estavam com problemas profundos. A confiança do consumidor despencou, a construção de habitação cessou, a demanda efetiva implodiu, as vendas no varejo caíram, o desemprego aumentou e as lojas e fábricas fecharam. Muitos dos tradicionais ícones da indústria dos EUA, como a General Motors, chegaram perto da falência, e um socorro temporário das montadoras de Detroit teve de ser organizado. A economia britânica estava igualmente com sérias dificuldades, e a União Europeia foi abalada, mesmo com níveis desiguais, com a Espanha e a Irlanda, juntamente com vários dos Estados orientais europeus que recentemente aderiram à União, mais seriamente afetados. A Islândia, cujos bancos tinham especulado nesses mercados financeiros, ficou totalmente falida.

A crise se estendeu por todo mundo capitalista, exigindo dos governos medidas de socorro aos grandes bancos e às multinacionais para evitar que houvesse uma derrocada mais profunda. Como consequência, nos países capitalistas, em especial nos periféricos, passou-se a especular sobre a necessidade da implementação de um forte ajuste fiscal que se baseasse no corte de direitos sociais, que passaram a ser tratados como gastos sociais e que, portanto, precisariam ser eliminados para reduzir a ação do Estado nessa esfera de atuação.

Nesse contexto, a privatização "passa a ser defendida como medida capaz de reduzir os gastos estatais e, ao mesmo tempo, garantir o pagamento da dívida pública, pelo ingresso da receita das privatizações (equilíbrio fiscal)" (LEHER, 2001, p. 158). Como consequência desse processo, a educação é incluída como serviço comercializável e sujeita a condições de competição. É oportuno ressaltar que o processo de expansão e privatização da educação superior se insere nas novas estratégias de acumulação de capital no setor educacional, por meio do mercado de capitais. Como parte desse processo, as instituições educacionais privadas vêm sendo estimuladas pelos governos a se expandirem, por meio da liberalização dos 
serviços educacionais, da desoneração fiscal e do sistema de crédito por meio do financiamento estudantil.

Por outro lado, deve-se ressaltar que o crescimento de vagas na educação superior oferecida pelo setor público é limitado pela riqueza nacional - apesar de existirem condições para sua ampliação, como prevê o Plano Nacional de Educação 2014-2024 (BRASIL, 2014). Ademais, as famílias brasileiras, em razão, ainda, da baixa renda per capita e de grande desigualdade e concentração de renda, atingiram a impossibilidade de ampliar o quantitativo de estudantes que pagam mensalidades nas instituições privadas (AMARAL, 2003).

\section{A EXPANSÃO DA EDUCAÇÃO SUPERIOR BRASILEIRA NOS GOVERNOS FHC, LULA E DILMA}

A adoção da política de expansão da educação superior brasileira por meio do setor privado, mais do que pelo setor público, foi iniciada durante a ditadura dos militares, como afirma Martins (2009, p. 23): "Entre 1965 e 1980, as matrículas do setor privado saltaram de 142 mil para 885 mil alunos, passando de $44 \%$ do total das matrículas para $64 \%$ nesse período".

Para Fonseca (1992), as modificações ocorridas nos campos político e econômico, no período da ditadura militar, tiveram como consequência a implementação de um projeto de desenvolvimento baseado no capital externo. Para dar sustentação a tal projeto, foi definida uma política educacional que pudesse assegurar a dominação, o controle social e, ao mesmo tempo, garantir a formação de mão de obra para o setor produtivo, com reduzido aporte de recursos públicos.

Desde então, vivencia-se, no Brasil, a adesão a uma política de expansão da educação superior que utiliza mais a via da privatização que a da subvenção pública ${ }^{6}$, o que favorece os governos a atender à demanda pelo acesso a esse nível de ensino, sem a ampliação significativa de recursos do fundo público. Esse processo teve continuidade em momentos posteriores à ditadura militar, como pode ser observado na Tabela 1, em que se apresenta a evolução da expansão das IES e das matrículas nos setores público e privado, nos governos FHC, LULA e DILMA. Há que se lembrar de que os governos FHC e LULA compreenderam períodos de oito anos e que o de DILMA completou, em 2014, quatro anos.

A Tabela 1 mostra a preponderância do setor privado na oferta desse nível de ensino no país, passando de $60,2 \%$ das matrículas, em 1995, para 74,9\%, em 2014. 
TABELA 1 - Evolução do número de Instituições de Educação Superior e matrículas(1) por categoria administrativa (público e privada). Brasil: 1994, 2002, 2003, 2010 e 2014.

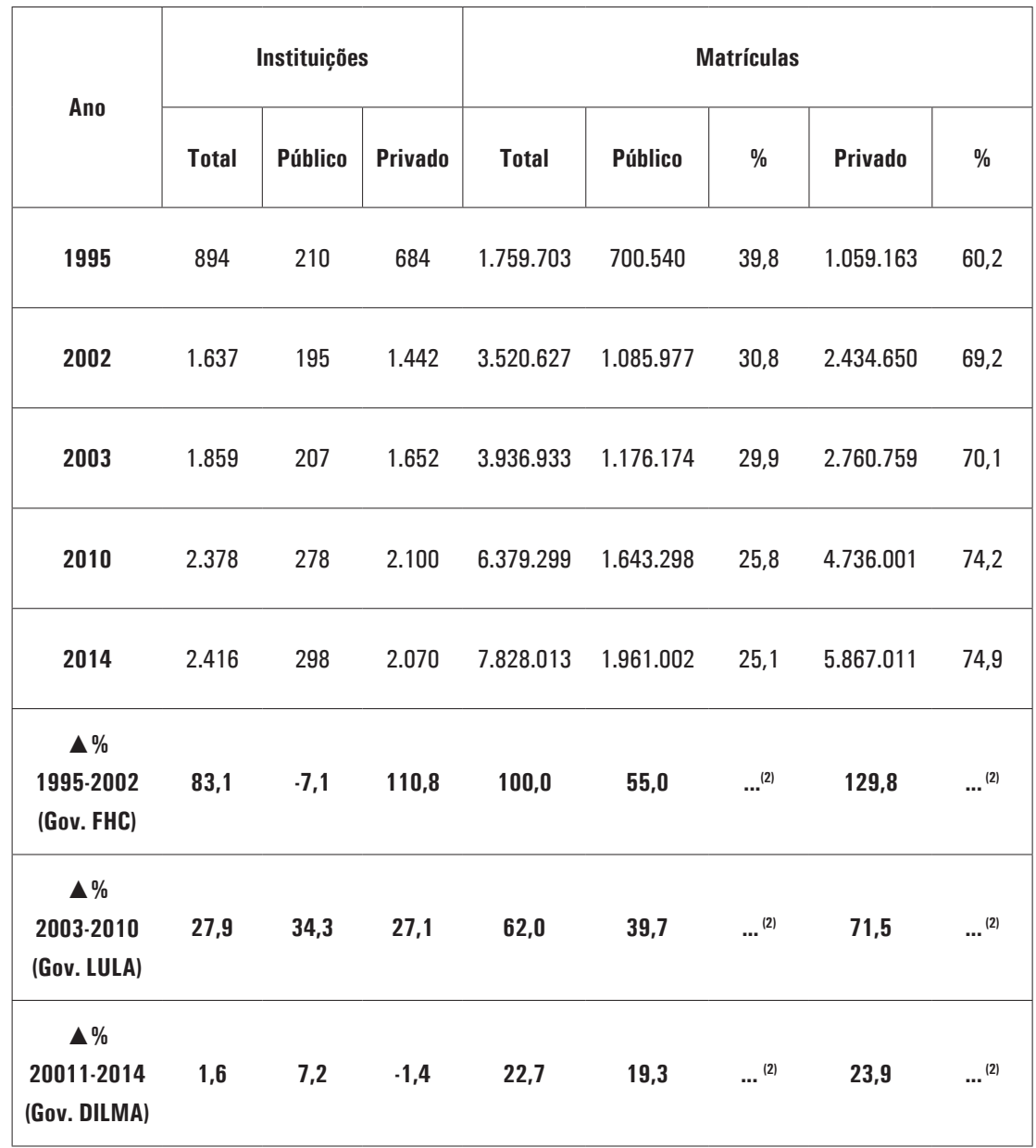

Fonte: MEC/INEP/DEAES, 1995; 2002; 2003; 2010; 2014.

Notas: ${ }^{(1)}$ Matrículas em cursos presenciais e a distância.

(2) ... - Não se aplica

A evolução dos números da educação superior, ao se analisar os três últimos governos do Brasil, apresentam diferentes níveis de crescimento percentual. O período dos governos de FHC (19952002) foi marcado pela redução do número de IES públicas $(-7,1 \%)$ e pelo aumento das IES privadas (110,8\%). Em relação a matrículas, observa-se um crescimento nos dois setores, com predominância no setor privado que expandiu $129,8 \%$ no número de estudantes matriculados, enquanto o setor público cresceu $55 \%$. 
No período de 2003 a 2010 (governo LULA), observa-se um crescimento maior no número de IES públicas, o que pode ser explicado pela criação de novas universidades federais e transformação dos Centros Federais de Educação Tecnológica (CEFETs) em Institutos Federais de Educação, Ciência e Tecnologia (IFs) ${ }^{7}$. Há uma diminuição relativa do crescimento de matrículas no setor privado, que continua maior, $71,5 \%$, em relação ao público, 39,7\%.

Ao fim de quatro anos de governo DILMA, novamente, cresce o número de instituições públicas e cai o número de privadas. Com relação às matrículas, há uma aproximação entre os percentuais de crescimento do setor público, 19,3\%, e do privado, 23,9\%. Há que se analisar, nesse movimento de percentuais, dois fatos relevantes: o número de matriculados no setor público passou de 1.085.977, em 2002, para 1.961.002, em 2014, um grande crescimento de 80,6\%; entretanto, mostrou-se insuficiente para elevar o percentual de matrículas do setor público em relação ao setor privado. Registrase, paralelamente, forte crescimento do setor privado, passando de 2.434.650 matrículas, em 2002, para 5.867.011, em 2014, 141\% de aumento, potencializado pelo financiamento às famílias, propiciado pelo ProUni e pelo FIES.

Essa expansão do setor privado mostra que,

Apesar de todos os problemas que causa, a expansão das instituições privadas continua a todo vapor. Graças a um sistema político dominado pelos interesses do capital, inclusive por meio do controle do financiamento eleitoral, o setor privatista é majoritário no Congresso Nacional e não se envergonha de apresentar propostas que respondem apenas aos interesses mercantis das instituições. (HELENE, 2011, texto eletrônico)

É interessante observarmos como essa expansão se apresenta em relação à organização acadêmica institucional, uma vez que, entre as orientações do Banco Mundial para a educação superior nos países da América Latina, está aquela que incentiva a oferta desse nível de ensino por meio de instituições privadas e pela diversificação institucional, como segue no trecho a seguir destacado:

A introdução de uma maior diferenciação no ensino superior, ou seja, a criação de instituições não universitárias e o aumento de instituições privadas, pode contribuir para satisfazer a demanda cada vez maior de educação superior e fazer com que os sistemas de ensino melhor se adequem às necessidades do mercado de trabalho. (BANCO MUNDIAL, 1995, p. 31)

Como mostrado na Tabela 2, no Brasil, também vem se materializando a proliferação das IES não universitárias. 
TABELA 2 - Evolução das IES no Brasil, por organização acadêmica (universidade e outras IES) e por categoria administrativa (pública e privada) - 2003/2014

\begin{tabular}{|c|c|c|c|c|c|c|c|c|c|c|}
\hline \multirow{3}{*}{$\begin{array}{c}\text { Ano } \\
\text { Total }\end{array}$} & \multicolumn{5}{|c|}{ UNIVERSIDADES } & \multicolumn{5}{|c|}{ OUTRAS IES } \\
\hline & \multirow{2}{*}{ Total } & \multicolumn{2}{|c|}{ Público } & \multicolumn{2}{|c|}{ Privado } & \multirow{2}{*}{ Total } & \multicolumn{2}{|c|}{ Público } & \multicolumn{2}{|c|}{ Privado } \\
\hline & & Núm. & $\%$ & Núm. & $\%$ & & Núm. & $\%$ & Núm. & $\%$ \\
\hline 1995 & 135 & 72 & 53,3 & 63 & 46,7 & 759 & 138 & 18,2 & 621 & 81,8 \\
\hline 2002 & 162 & 78 & 48,1 & 84 & 51,9 & 1.475 & 117 & 7,9 & 1.358 & 92,1 \\
\hline 2003 & 163 & 79 & 48,5 & 84 & 51,5 & 1.696 & 128 & 7,5 & 1.568 & 92,5 \\
\hline 2010 & 190 & 101 & 53,2 & 89 & 46,8 & 2.188 & 177 & 8,1 & 2.011 & 91,9 \\
\hline 2014 & 195 & 111 & 56,9 & 84 & 43,1 & 2.173 & 187 & 8,6 & 1.986 & 91,4 \\
\hline $\begin{array}{c}\Delta \% \\
1995 \\
2014\end{array}$ & 44,4 & 54,2 & $\ldots{ }^{(*)}$ & 33,3 & $\ldots{ }^{(*)}$ & 186,3 & 35,5 & $\ldots{ }^{(*)}$ & 219,8 & $\ldots{ }^{(*)}$ \\
\hline
\end{tabular}

Fonte: MEC/INEP, 1995; 2012; 2003; 2010; 2014.

Nota: ${ }^{\left({ }^{*}\right)}$... - Não se aplica dado numérico.

A Tabela 2 mostra que a expansão no número de instituições, evidenciada na Tabela 1, foi, principalmente, consequência do crescimentodeinstituiçõesnãouniversitárias(outrasIES), especialmente no setor privado. Como vemos, o número de universidades teve crescimento de 54,2\%, no setor público, no período de 1995 a 2014, e de $33,3 \%$, no setor privado. Diferente comportamento se observa no setor privado que cresceu nos governos de FHC, de 63 para 84 universidades; nos governos de Lula, de 84 para 89 universidades; e uma redução de 89 para 84 , retornando ao mesmo número do ano de 2002, 84 universidades, final dos dois mandatos de FHC.

Em contrapartida, o quantitativo de Outras IES, do setor privado, apresentou um crescimento muito maior, com uma expansão 
de 219,8\% no período de 1995 a 2014. No ano de 1995, representava $81,8 \%$ das Outras IES, passando a constituir mais de $90 \%$ nos demais anos da análise. No setor público, o aumento no número de Outras IES foi bem menor, de 35,5\%. Deve-se destacar que, no governo FHC, houve a maior expansão, passando de 621 para 1.358 instituições, um aumento de $118,7 \%$, e que, no governo Dilma, houve uma pequena redução, de 2011 para 1986 instituições.

Esse modelo de expansão por meio da diversificação institucional, sobretudo por aquelas não universitárias, está presente no receituário do Banco Mundial e se dá por representar menores custos e maiores lucros, o que interessa ao setor privado-mercantil que possui, historicamente, no Brasil, presença marcante na educação superior, em especial a partir da ditadura militar de 1964. Esse processo evidencia, mais uma vez, uma educação superior concebida como mercadoria que visa à garantia de lucro ao capitalista; e para tanto, torna-se necessário rebaixar as exigências de acesso e de formação, priorizando o ensino em detrimento da pesquisa. Essa conformação pretende atender as camadas populacionais que estão excluídas desse nível de ensino por não terem tempo, condições financeiras "ou preparo para enfrentar um concurso vestibular em igualdade de condições com alunos advindos de um ensino médio de qualidade. Assim, tem-se uma educação superior rápida e mais barata para os que dela necessitam, ou seja, os mais pobres" (ALGEBAILE, 2007, p. 105).

Merece destaque, ainda, a redução do crescimento das IES privadas, tanto as universidades como as Outras IES, o que pode ser explicado pelo movimento de fusões das IES desse setor, como consequência do processo de financeirização que o atingiu, a partir do ano de 2007, com a criação de redes de empresas por meio da compra e/ou fusão de IES privadas do país. Essas empresas tiveram seu capital ampliado após aderirem ao mercado de ações (Bolsa de Valores de São Paulo - BOVESPA), o que possibilitou a compra de instituições de menor porte como também a fusão de grandes universidades, formando vultosos grupos empresariais cuja tendência é a formação de oligopólios que terão o monopólio do mercado desse nível educacional, no país, como apontam alguns estudos feitos ${ }^{8}$.

Como parte desse processo, observa-se a expansão do domínio do capital estrangeiro sobre a educação do Brasil por meio da compra de ações pelos fundos de investimentos e por empresas educacionais transnacionais. A compra, no ano de 2011, de 28\% das ações da Kroton Educacional pelo fundo de investimentos norte-americano Advent 
International é um exemplo claro desse processo de financeirização por meio da entrada de capitais estrangeiros na educação superior brasileira.

A expansão do setor privado-mercantil no Brasil é, portanto, estimulada pelas políticas implementadas pelos sucessivos governos, ao promoverem uma política de renúncia tributária e de financiamento direto aos estudantes, por meio do ProUnie doFIES, que subvencionam parcela significativa de estudantes dessas instituições.

\section{OS PROGRAMAS FIES E PROUNI NO FINANCIAMENTO DO ENSINO SUPERIOR PRIVADO BRASILEIRO}

A Pesquisa Nacional por Amostra de Domicílios (PNAD) de 2014 mostrou que o quantitativo de jovens brasileiros com idade entre 18 e 24 anos era de 22.681 .790 pessoas (IBGE, 2016) e que estavam matriculados na educação superior (ES) um total de 3.984 .707 jovens nessa faixa etária. Isso resulta em uma taxa líquida de 17,6\%, que é o número de jovens com idade entre 18 e 24 anos matriculados na ES, dividido pelo número de jovens nessa faixa etária, na população. Essa taxa líquida é pequena, se comparada com a meta de atingir $30 \%$, prevista no Plano Nacional de Educação que se encerrou em 2011, e com a de chegar a 33\%, em 2024, meta do Plano aprovado em 2014 - o PNE 2014-2024, por meio da Lei no 13.005, de 24 de junho desse ano.

Pressionados por uma tríplice vertente - a das famílias que não podem pagar mensalidades nas instituições privadas (AMARAL, 2003), a dos empresários-mercantis que se veem às voltas com vagas ociosas e grande inadimplência (CARVALHO, 2006) e por aqueles que defendem a ampliação das matrículas públicas -, os governos FHC, LULA e DILMA reagiram de forma a tentar responder a essas pressões.

No governo FHC, como já analisamos, a ampliação das matrículas públicas foi de 55,0\%, em face de 129,8\% de ampliação nas matrículas privadas, e criou-se o Fundo de Financiamento Estudantil (FIES), pela Medida Provisória n ${ }^{\circ} 1.827$, de 27 de maio de 1999, transformada na Lei no 10.260 , de 12 de julho de 2001. No seu artigo $1^{\circ}$, tal lei determina ser ele "destinado à concessão de financiamento a estudantes regularmente matriculados em cursos superiores não gratuitos e com avaliação positiva nos processos conduzidos pelo Ministério da Educação, de acordo com regulamentação própria" (BRASIL, 2001). O FIES substituiu o Programa de Crédito Educativo, criado, em 1992, pela Lei no 8.436, de 25 de junho (BRASIL, 1992).

No governo LULA, a ampliação das matrículas públicas foi de 
$39,7 \%$ e, nas privadas, de $71,5 \%$, evidenciando uma diferença maior entre o privado e o público. O governo LULA continuou implementando o FIES e criou o Programa Universidade para Todos (ProUni), por meio da Medida Provisória n ${ }^{\circ}$ 213, de 10 de setembro de 2004, convertida na Lei no 11.096, de 13 de janeiro de 2005. Seu artigo $1^{\circ}$ determina ser o ProUni "destinado à concessão de bolsas de estudos integrais e bolsas de estudos parciais de 50\% (cinquenta por cento) ou de $25 \%$ (vinte e cinco por cento) para estudantes de cursos de graduação e sequenciais de formação específica, em instituições privadas de ensino superior, com ou sem fins lucrativos" (BRASIL, 2005).

No governo DILMA, até o ano de 2014, houve elevação de $19,3 \%$ nas matrículas públicas e de $23,9 \%$ nas privadas. O governo DILMA manteve o FIES e o ProUni, elevando substancialmente o volume de recursos associados a esse Fundo, como veremos a seguir.

Verifica-se, portanto, que as pressões das famílias e dos empresários prevaleceram nesse contexto (CARVALHO, 2006); como já afirmamos, a expansão das matrículas públicas foi sempre menor que a expansão privada.

\section{O FIES e seus recursos financeiros}

O FIES é composto por recursos financeiros que possuem, como definido no artigo $2^{\circ}$, da Lei no $10.260 / 2001$, as seguintes fontes:

I - dotações orçamentárias consignadas ao MEC [...];

II - trinta por cento da renda líquida dos concursos de prognósticos administrados pela Caixa Econômica Federal [...];

III - encargos e sanções contratualmente cobrados nos financiamentos concedidos [...];

IV - taxas e emolumentos cobrados dos participantes [...];

$\mathrm{V}$ - encargos e sanções contratualmente cobrados [...];

VI - rendimentos de aplicações financeiras sobre suas disponibilidades;

VII - receitas patrimoniais;

VIII - outras receitas. (BRASIL, 2001)

Além desses aportes, a citada Lei $\mathrm{n}^{\circ}$. 10.260, em seu artigo $7^{\circ}$, autorizou a União "a emitir títulos da dívida pública em favor do FIES" (BRASIL, 2001). Os títulos emitidos se destinam ao pagamento das mantenedoras das IES, que os utilizarão para pagar contribuições sociais e poderão, ainda, nos termos do artigo 10, da mesma lei, ser utilizados "para o pagamento de quaisquer tributos 
administrados pela Receita Federal do Brasil" (BRASIL, 2001). Ademais, no contexto dos recursos financeiros, há o pagamento de uma taxa de administração aos agentes financeiros do Fundo, a saber, o Banco do Brasil e a Caixa Econômica Federal.

1) No Boletim Legislativo $n^{\circ} 26$, de 2015 , há a descrição detalhada do mecanismo que "não paga às escolas em dinheiro, mas sim entregando-lhes um título do Tesouro Nacional (Certificado do Tesouro Nacional - CFT, série E)" (MENDES, 2015, Anexo 1). O boletim informa ainda que os CFT série E "são títulos com valor unitário $\mathrm{R} \$ 1,00$ e atualização mensal pelo IGP-M”. O mecanismo detalhado no boletim, conforme consta na Lei $\mathrm{n}$ 10.260/2001, é o seguinte:

2) O FIES solicita ao Tesouro a emissão de uma dada quantidade/valor de CFT, pagando ao Tesouro por esses títulos com seus recursos orçamentários (o que representa um desembolso do FIES registrado no orçamento) $-\operatorname{art.} 7^{\circ}, \S 3^{\circ}$.

3) Ao receber esses recursos, o Tesouro Nacional os utilizará exclusivamente no resgate de outros títulos da dívida pública - art. $7^{\circ}$. $\$ 3^{\circ}$. Ou seja, para o Tesouro tudo se passa como se fosse uma troca de um tipo de título da dívida pública (NTN, LFT, etc. que são resgatados) por outro tipo de título da dívida pública (CFT, que são emitidos). Em termos líquidos, não se altera o estoque da dívida pública total.

4) O FIES entrega os títulos às escolas, em valor equivalente ao pagamento das mensalidades (art. $9^{\circ}$.) e passa a ter um crédito junto ao aluno financiado, que repagará o empréstimo no prazo contratado. Todas as amortizações feitas pelos alunos entram no orçamento do FIES como receita vinculada ao Fundo.

5) A escola utiliza os títulos exclusivamente para o pagamento de tributos e contribuições previdenciárias - art. 10.

6) Para atender ao caso em que haja escolas com mais CFT do que dívidas tributárias e previdenciárias a pagar, o Fundo Nacional de Desenvolvimento da Educação (FNDE), agente operado do FIES, promove rodadas trimestrais de recompra desses títulos, pagando em dinheiro às escolas - art. 13. (MENDES, 2015, Anexo 1)

A Tabela 3, abaixo, mostra a evolução dos valores financeiros que estiveram presentes, no âmbito do FIES, no período 20002015, separando-os em valores utilizados para o pagamento da administração do Fundo perante os agentes financeiros e valores dedicados ao financiamento dos estudantes. Tais montantes englobam tanto os recursos previstos no artigo $2^{\circ}$, da Lei $n^{\circ}$ 10.260/2001, quanto o volume de recursos associados aos títulos da dívida pública que foram emitidos em nome das mantenedoras e que são caracterizados como Operações Especiais: financiamento com retorno (BRASIL; CÂMARA DOS DEPUTADOS, 2016). 
TABELA 3 - Recursos financeiros associados ao FIES administração e financiamento dos estudantes

(Valores em R\$, a preços de janeiro de 2016, corrigidos pelo IPCA)

\begin{tabular}{c|c|c|c}
\hline Ano & $\begin{array}{c}\text { Recursos para a } \\
\text { administração do FIES }\end{array}$ & $\begin{array}{c}\text { Recursos para o } \\
\text { financiamento dos } \\
\text { estudantes }\end{array}$ & Total \\
\hline $\mathbf{2 0 0 0}$ & 11.376 .836 & 2.365 .682 .279 & 2.377 .059 .114 \\
\hline $\mathbf{2 0 0 1}$ & 28.530 .061 & 1.189 .604 .694 & 1.218 .134 .755 \\
\hline $\mathbf{2 0 0 2}$ & 50.422 .428 & 1.406 .894 .383 & 1.457 .316 .811 \\
\hline $\mathbf{2 0 0 3}$ & 69.321 .462 & 1.415 .935 .122 & 1.485 .256 .583 \\
\hline $\mathbf{2 0 0 4}$ & 73.743 .338 & 1.296 .388 .819 & 1.370 .132 .157 \\
\hline $\mathbf{2 0 0 5}$ & 115.723 .279 & 1.330 .024 .014 & 1.445 .747 .294 \\
\hline $\mathbf{2 0 0 6}$ & 94.583 .704 & 1.516 .352 .926 & 1.610 .936 .630 \\
\hline $\mathbf{2 0 0 7}$ & 189.920 .690 & 1.460 .192 .991 & 1.650 .113 .681 \\
\hline $\mathbf{2 0 0 8}$ & 169.008 .727 & 1.712 .717 .215 & 1.881 .725 .942 \\
\hline $\mathbf{2 0 0 9}$ & 146.741 .491 & 1.981 .788 .327 & 2.128 .529 .818 \\
\hline $\mathbf{2 0 1 0}$ & 170.090 .828 & 2.349 .882 .226 & 2.519 .973 .054 \\
\hline $\mathbf{2 0 1 1}$ & 196.703 .015 & 3.182 .597 .320 & 3.379 .300 .335 \\
\hline $\mathbf{2 0 1 2}$ & 229.465 .125 & 6.734 .268 .859 & 6.963 .733 .984 \\
\hline $\mathbf{2 0 1 3}$ & 333.184 .042 & 8.935 .598 .047 & 9.268 .782 .089 \\
\hline $\mathbf{2 0 1 4}$ & 138.124 .540 & 13.964 .986 .186 & 14.103 .110 .726 \\
\hline $\mathbf{2 0 1 5}$ & 820.027 .320 & 14.709 .583 .082 & 15.529 .610 .402 \\
\hline
\end{tabular}

Fonte: Execução Orçamentária da União - 2000-2015. (BRASIL; CÂMARA DOS DEPUTADOS, 2016).

O Gráfico 1 ilustra a evolução do valor total do FIES nesse período.

GRÁFICO 1 - Recursos financeiros totais associados ao FIES

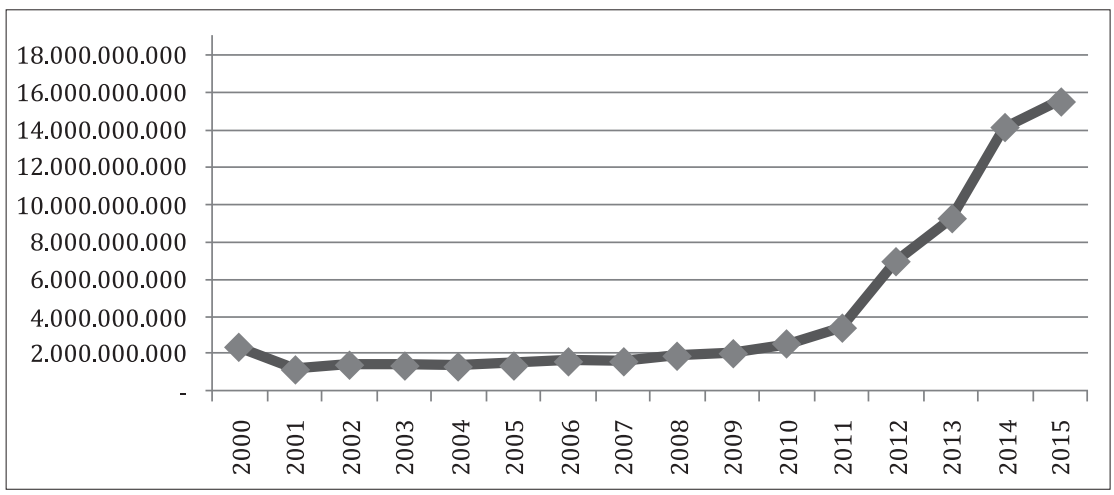

Fonte: Elaboração pelos autores deste artigo a partir dos valores da Tabela 3.

Verifica-se, portanto, que há, nesse processo, um grande valor financeiro vinculado ao FIES que se dirige às IES privadas, tendo grande expansão a partir de 2012. Apesar desses valores não significarem recursos financeiros fluindo diretamente para os empresários, são recursos da União que se dirigem ao pagamento dos 
títulos do Tesouro. No fim, pode-se afirmar que existe uma renúncia tributária temporária, esperando-se que, ao longo do tempo, os recursos financeiros retornem aos cofres da União pelo pagamento dos empréstimos. Entretanto, a experiência do Crédito Educativo mostrou que a possibilidade de inadimplência é elevada, tendo chegado a 83\%, em 1997, ano final desse programa (BARROS, 2003).

\section{O ProUni e seus recursos financeiros}

O Programa Universidade para Todos (ProUni), instituído pela Lei $\mathrm{n}^{\circ} 11.096$, de 13 de janeiro de 2005, concede bolsas de estudos que não se vinculam a qualquer contrapartida posterior do estudante - ou seja, não é um empréstimo, como o FIES.

As instituições de educação superior, tanto as sem fins lucrativos quanto as com fins lucrativos, podem aderir ao ProUni e ficam isentas dos pagamentos dos seguintes tributos (impostos e contribuições): I - Imposto de Renda das Pessoas Jurídicas (IRPJ); II Contribuição Social sobre o Lucro Líquido (CSLL); III - Contribuição Social para Financiamento da Seguridade Social (COFINS); e IV Contribuição para o Programa de Integração Social (PIS-PASEP). A legislação estabelece ainda que a isenção "será calculada na proporção da ocupação efetiva das bolsas devidas” (BRASIL, 2005).

A Tabela 4 mostra a evolução dos totais das isenções tributárias de cada um dos tributos, no período 2006-2015.

TABELA 4 - Isenções tributárias no âmbito do ProUni (2006-2015) (Valores em R\$, a preços de janeiro de 2016, corrigidos pelo IPCA)

\begin{tabular}{c|c|c|c|c|c}
\hline Ano & IRPJ & CSLL & COFINS & PIS.PASEP & Total \\
\hline 2006 & 82.594 .530 & 34.966 .974 & 96.168 .307 & 254.757 .556 & 468.487 .367 \\
\hline 2007 & 51.862 .156 & 21.018 .155 & 101.601 .383 & 39.931 .813 & 214.413 .507 \\
\hline 2008 & 165.292 .119 & 85.469 .571 & 224.185 .085 & 49.452 .406 & 524.399 .180 \\
\hline 2009 & 228.692 .436 & 132.009 .148 & 337.285 .634 & 73.415 .899 & 771.403 .117 \\
\hline 2010 & 276.864 .765 & 18.052 .285 & 380.355 .708 & 82.763 .293 & 758.036 .050 \\
\hline 2011 & 301.135 .110 & 107.708 .310 & 238.990 .525 & 52.130 .202 & 699.964 .148 \\
\hline 2012 & 355.668 .203 & 164.332 .915 & 356.665 .580 & 77.277 .542 & 953.944 .241 \\
\hline 2013 & 386.819 .100 & 133.688 .961 & 327.585 .930 & 70.976 .952 & 919.070 .943 \\
\hline 2014 & 240.939 .682 & 72.049 .043 & 311.442 .555 & 67.479 .220 & 691.910 .500 \\
\hline 2015 & 417.211 .405 & 132.082 .577 & 390.400 .694 & 84.625 .116 & 1.024 .319 .793 \\
\hline
\end{tabular}

Fonte: Demonstrativos dos Gastos Tributários - 2006-2015. (BRASIL; MF; RFB, 2016).

O Gráfico 2 ilustra a evolução do valor total das isenções tributárias associadas ao ProUni. 
GRÁFICO 2 - Isenções tributárias no âmbito do ProUni (2006-2015)

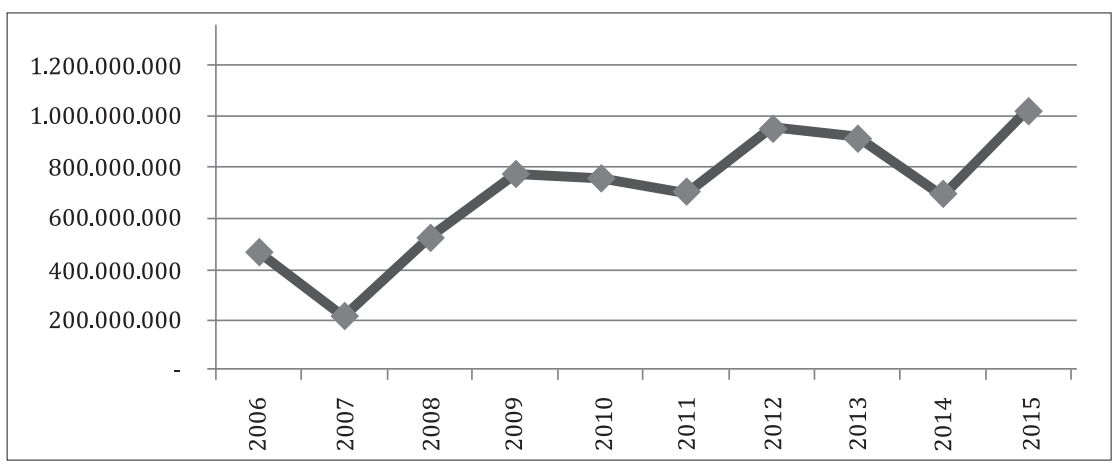

Fonte: Elaboração pelos autores deste artigo a partir dos dados da Tabela 4.

Nota-se, portanto, que esse conjunto de isenções já havia ultrapassado, em 2015, o marco de R \$ 1 bilhão.

Há duas vertentes a serem analisadas nesse conjunto de isenções oferecidas no pagamento das bolsas às IES privadas. Há uma isenção do IRPJ, que faz parte do conjunto de impostos vinculados à educação, no contexto da União, e há isenções de contribuições que não possuem vinculações com a educação. Portanto, ao serem dirigidas à educação, são desviadas de suas destinações específicas, sendo deslocados para o pagamento das bolsas educacionais.

\section{Os recursos da Função Educação e os recursos do FIES e do ProUni}

Os entes federados, ao executarem os seus orçamentos, classificam as suas despesas em diversas funções, sendo uma delas a Função Educação. A União lança, nessa Função, os recursos totais aplicados nas instituições educativas federais - universidades, institutos federais etc. -, os valores repassados ao Fundo de Manutenção e Desenvolvimento da Educação Básica e de Valorização dos Profissionais da Educação (Fundeb), ao FIES, à estrutura do MEC etc. Entretanto, os lançamentos efetivados nessa Função não são somente aqueles associados à Manutenção e Desenvolvimento do Ensino (MDE), como definido no artigo 212, da Constituição Federal (BRASIL, 1988), e no artigo 70, da Lei de Diretrizes e Bases, e devem, portanto, ser descontados, se o objetivo for o de se obter o valor de MDE.

A análise dos recursos associados ao ProUni e ao FIES, comparados ao montante de recursos da Função Educação, nos permite aquilatar o tamanho desses dois programas, que dirigem recursos, em forma de títulos da dívida pública, o FIES, ou de isenções tributárias, o ProUni, para as instituições privadas de educação superior. 
A Tabela 5 mostra os valores totais lançados na Função Educação, no período 2006-2015, período em que foram, simultaneamente, vinculados valores para o FIES e para o ProUni.

TABELA 5 - Valores empenhados pela União na Função Educação

(Valores em R\$, a preços de janeiro de 2016, corrigidos pelo IPCA)

\begin{tabular}{l|c}
\hline Ano & Função Educação \\
\hline $\mathbf{2 0 0 6}$ & 34.671 .882 .845 \\
\hline $\mathbf{2 0 0 7}$ & 41.425 .377 .718 \\
\hline $\mathbf{2 0 0 8}$ & 45.472 .815 .220 \\
\hline $\mathbf{2 0 0 9}$ & 56.288 .390 .376 \\
\hline $\mathbf{2 0 1 0}$ & 70.860 .231 .561 \\
\hline $\mathbf{2 0 1 1}$ & 80.085 .198 .383 \\
\hline $\mathbf{2 0 1 2}$ & 94.335 .209 .405 \\
\hline $\mathbf{2 0 1 3}$ & 100.667 .015 .796 \\
\hline $\mathbf{2 0 1 4}$ & 108.079 .334 .217 \\
\hline $\mathbf{2 0 1 5}$ & 109.561 .074 .212 \\
\hline
\end{tabular}

Fonte: Relatórios Resumidos da Execução Orçamentária - 2006-2015. (BRASIL; MF; STN, 2016).

O Gráfico 3 ilustra a evolução desses valores associados à Função Educação.

GRÁFICO 3 -Valores empenhados pela União na Função Educação

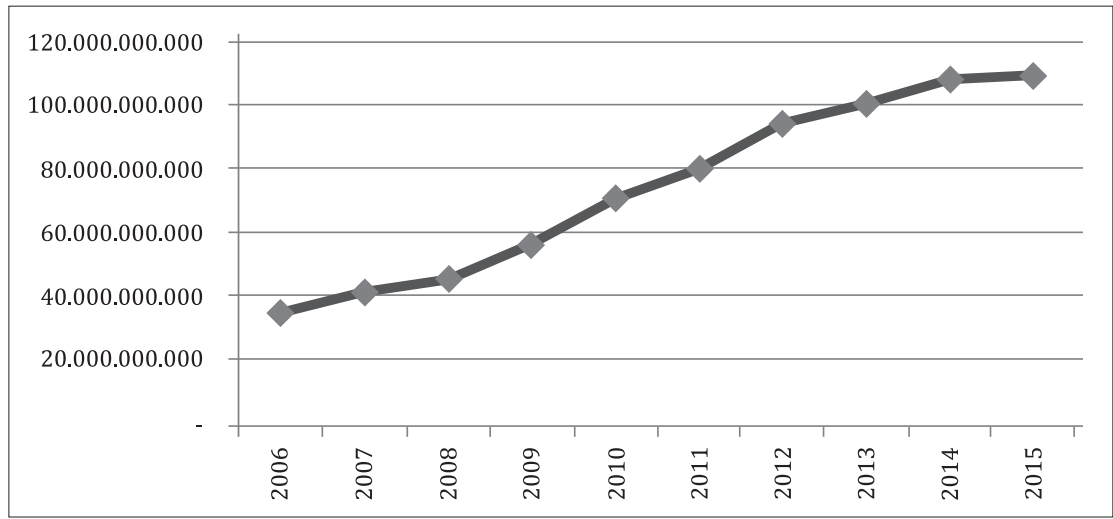

Fonte: Elaboração pelos autores deste artigo a partir dos dados da Tabela 5.

Nota-se que houve uma mudança de patamar nos valores dessa Função, saindo esses da ordem de R $\$ 40$ bilhões, em 2006, para quantitativos superiores a $\mathrm{R} \$ 100$ bilhões, em 2015. Ressalte-se que estão lançados, nesses montantes, os próprios valores pertinentes ao FIES e, também, os relacionados à complementação da União para o Fundeb, da ordem de R\$12 bilhões (MENDES, 2015). 
A Tabela 6 apresenta os valores da Função Educação e aqueles associados ao FIES, além do percentual relativo ao total da Função.

TABELA 6 - Recursos totais envolvidos no FIES como percentual da Função Educação

(Valores em R\$, a preços de janeiro de 2016, corrigidos pelo IPCA)

\begin{tabular}{c|c|c|c}
\hline Ano & Funçäo Educação & TOTAL FIES & $\%$ \\
\hline $\mathbf{2 0 0 6}$ & 34.671 .882 .845 & 1.610 .936 .630 & 4,6 \\
\hline $\mathbf{2 0 0 7}$ & 41.425 .377 .718 & 1.650 .113 .681 & 4,0 \\
\hline $\mathbf{2 0 0 8}$ & 45.472 .815 .220 & 1.881 .725 .942 & 4,1 \\
\hline $\mathbf{2 0 0 9}$ & 56.288 .390 .376 & 2.128 .529 .818 & 3,8 \\
\hline $\mathbf{2 0 1 0}$ & 70.860 .231 .561 & 2.519 .973 .054 & 3,6 \\
\hline $\mathbf{2 0 1 1}$ & 80.085 .198 .383 & 3.379 .300 .335 & 4,2 \\
\hline $\mathbf{2 0 1 2}$ & 94.335 .209 .405 & 6.963 .733 .984 & 7,4 \\
\hline $\mathbf{2 0 1 3}$ & 100.667 .015 .796 & 9.268 .782 .089 & 9,2 \\
\hline $\mathbf{2 0 1 4}$ & 108.079 .334 .217 & 14.103 .110 .726 & 13,0 \\
\hline $\mathbf{2 0 1 5}$ & 109.561 .074 .212 & 15.529 .610 .402 & 14,2 \\
\hline
\end{tabular}

Fonte: Elaboração pelos autores deste artigo a partir de dados das Tabelas 2 e 4.

O valor do FIES de 2015, da ordem de R\$ 15 bilhões, é superior à complementação da União ao Fundeb, que é da ordem de $\mathrm{R} \$ 12$ bilhões. Isso mostra a abrangência que tomou esse programa de financiamento estudantil, no âmbito da educação superior, comparado ao financiamento complementar da União para a educação básica oferecida por estados e municípios.

O Gráfico 4 ilustra a evolução dos percentuais.

GRÁFICO 4 - Recursos totais envolvidos no FIES como percentual da Função Educação

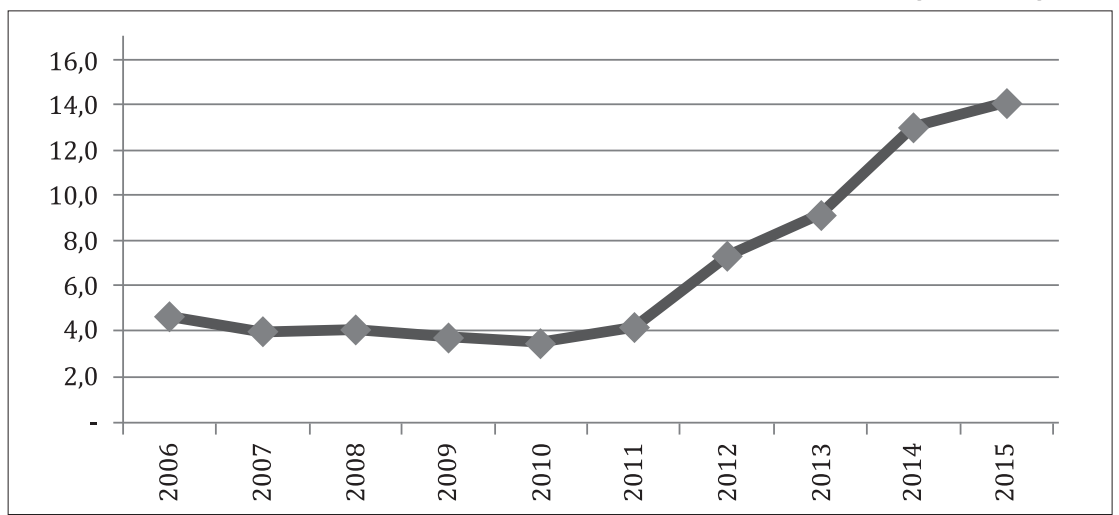

Fonte: Elaboração pelos autores deste artigo a partir dos dados da Tabela 6.

Verifica-se que, de 2006 a 2011, os recursos do FIES foram estáveis e da ordem de 4\% do total da Função Educação, elevando-se substancialmente, atingindo 14,2\%, em 2015. 
Devemos lembrar, entretanto, que os recursos associados ao FIES são empréstimos e há que se realizar novos estudos para acompanhar a evolução dos recursos do Fundo relativos à inadimplência.

A Tabela 7 faz a comparação da Função Educação com as renúncias tributárias associadas ao ProUni.

TABELA 7 - Os recursos de isenções tributárias envolvidos no ProUni como percentual da Função Educação

(Valores em R\$, a preços de janeiro de 2016, corrigidos pelo IPCA)

\begin{tabular}{c|c|c|c}
\hline Ano & Função Educação & TOTAL ProUni & $\%$ \\
\hline $\mathbf{2 0 0 6}$ & 34.671 .882 .845 & 468.487 .367 & 1,4 \\
\hline $\mathbf{2 0 0 7}$ & 41.425 .377 .718 & 214.413 .507 & 0,5 \\
\hline $\mathbf{2 0 0 8}$ & 45.472 .815 .220 & 524.399 .180 & 1,2 \\
\hline $\mathbf{2 0 0 9}$ & 56.288 .390 .376 & 771.403 .117 & 1,4 \\
\hline $\mathbf{2 0 1 0}$ & 70.860 .231 .561 & 758.036 .050 & 1,1 \\
\hline $\mathbf{2 0 1 1}$ & 80.085 .198 .383 & 699.964 .148 & 0,9 \\
\hline $\mathbf{2 0 1 2}$ & 94.335 .209 .405 & 953.944 .241 & 1,0 \\
\hline $\mathbf{2 0 1 3}$ & 100.667 .015 .796 & 919.070 .943 & 0,9 \\
\hline $\mathbf{2 0 1 4}$ & 108.079 .334 .217 & 691.910 .500 & 0,6 \\
\hline $\mathbf{2 0 1 5}$ & 109.561 .074 .212 & 1.024 .319 .793 & 0,9 \\
\hline
\end{tabular}

Fonte: Elaboração pelos autores deste artigo a partir de dados das Tabelas 4 e 5

O Gráfico 5 ilustra a evolução do percentual da Tabela 7.

GRÁFICO 5 - Os recursos de isenções tributárias envolvidos no ProUni como percentual da Função Educação

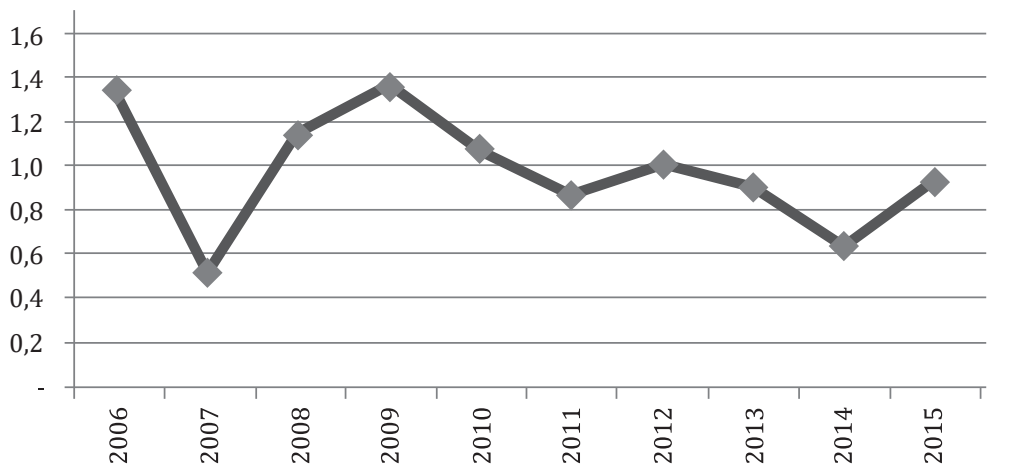

Fonte: Elaboração pelos autores deste artigo a partir dos dados da Tabela 7.

Há, portanto, uma oscilação do percentual, atingindo valores máximos equivalentes a 1,4\% e um valor mínimo equivalente a $0,5 \%$, alcançando, em 2015, 0,9\% do valor da Função Educação. 
O patamar de renúncia tributária atingida no programa ProUni ultrapassou $\mathrm{R} \$ 1$ bilhão, em 2015 , o que, apesar de representar o equivalente a apenas $0,9 \%$ do total da Função Educação, torna-se relevante por significar um valor que deve ser adicionado aos R $\$ 15$ bilhões do FIES. Ademais, não possui a possibilidade de retorno ao Fundo Público por se constituir em uma permuta por bolsas no setor privado.

\section{CONSIDERACְ̃̃ES FINAIS}

As análises realizadas no estudo relatado mostram que a expansão da educação superior brasileira, no longo período de 1995 a 2014, quase duas décadas, encontra-se ainda fortemente vinculada ao setor privado, uma vez que, apesar das expansões ocorridas no setor público, continua-se ampliando o percentual relativo de matrículas, chegando, em 2014, a 74,9\% do total de alunos matriculados. O setor privado, salvo exceções, é constituído de instituições que não promovem atividades que fazem a interligação do ensino, da pesquisa e da extensão, e, para verificar isso, é só examinar estatísticas da Coordenação de Aperfeiçoamento de Pessoal de Nível Superior (Capes) que mostram que, em 2014, dos alunos de pós-graduação stricto sensu, 81,2\% estudavam em instituições públicas (CAPES, 2016). A pós-graduação é o principal elo, no âmbito da educação superior, entre o ensino, a pesquisa e a extensão; dessa forma, incentivar o crescimento do setor privado significa incrementar o número de jovens que terão uma formação em ambientes desprovidos da riqueza dessa articulação.

A taxa líquida, em 2014, como vimos, alcançou o valor de $17,6 \%$, o que é ainda muito distante da meta de atingir $33 \%$, considerando o PNE (2014-2024), o que indica a existência de um longo caminho a ser percorrido e que exigirá, até 2024, grande expansão da educação superior no país.

Pode-se afirmar que o grande volume de recursos associados ao FIES e ao ProUni que se dirigem às instituições privadas contribuiu de forma fundamental para que o quantitativo de matrículas continuasse a aumentar mais no setor privado que no público. No ano de 2015, o total de recursos associados aos dois programas atingiu $\mathrm{R} \$ 16,5$ bilhões, significando em torno de 15\% dos recursos empenhados pelo governo federal na Função Educação, valor significativo, em face dos R \$ 12 bilhões de complementação ao Fundeb, realizado pela União.

Apesar da ressalva de que os recursos associados ao FIES significam empréstimos e que contribuem para aumentar a dívida pública do país, sabe-se, também, que, historicamente, esse tipo de 
transação trará em seu bojo um alto índice de inadimplência, a ser conferida em estudos futuros sobre o FIES.

O PNE (2014-2024) tem como uma de suas metas atingir uma taxa líquida de 33\%, uma taxa bruta de $50 \%$, e $40 \%$ das novas matrículas precisam ocorrer no setor público. Há, portanto, que se elevar o quantitativo de matrículas públicas mais que as privadas, e isso só será possível se os recursos públicos se dirigirem às instituições públicas, interrompendo esse percurso estabelecido, desde 1995, por meio da relação público-privado.

\section{REFERÊNCIAS}

ALGEBAILE, M. E. B. Expansão da educação superior: traços de uma inclusão seletiva no cenário educacional brasileiro. In: VIEITZ, C. G.; BARONE, R. E. M. (Org.). Educação e políticas públicas: tópicos para o debate. Araraquara: Junqueira \& Marin, 2007. p. 93-119.

AMARAL, N. C. Financiamento da educação superior: Estado X mercado. São Paulo: Cortez; Piracicaba: Unimep, 2003.

BANCO MUNDIAL. La enseñanza superior: las lecciones derivadas de la experiencia. 1. ed. [in Spanish]. Washington, D.C.: 1995. (Serie: El desarrollo en la práctica).

BARROS, H. H. D. Financiamento estudantil: estudo da Consultoria Legislativa da Câmara dos Deputados. Brasília-DF: Câmara dos Deputados, set. 2003. 6p.

BRAGA, J. C. de. S. Temporalidade da riqueza: teoria da dinâmica e financeirização do capitalismo. Campinas: Editora Unicamp, 2000. 342p.

BRASIL. Ministério da Fazenda (MF). Secretaria do Tesouro Nacional (STN). Relatório Resumido da Execução Orçamentária (2006-2015), 2016. [Documentos eletrônicos]. Brasília: MF: STN. Disponível em: <http://www.tesouro.fazenda.gov.br/-/relatorioresumido-de-execucao-orcamentaria>. Acesso em: 18 jan. 2016.

BRASIL. Ministério da Fazenda (MF). Receita Federal do Brasil (RFB). Demonstrativos dos Gastos Tributários - DGT, 2016. [Documentos eletrônicos]. Brasília: MF: RFB. Disponível em: <http://idg.receita.fazenda.gov.br/dados/receitadata/renuncia-fiscal/ previsoes-ploa/arquivos-e-imagens/demonstrativos-dos-gastos-tributarios-dgt $>$. Acesso em: 10 jan. 2016.

BRASIL. Câmara dos Deputados. Execução Orçamentária da União (2000-2015), 2016. [Documentos eletrônicos]. Disponível em: <http://www2.camara.leg.br/atividadelegislativa/orcamentobrasil >. Acesso em: 15 jan. 2016.

BRASIL. Lei $\mathbf{n}^{\mathbf{0}}$ 13.005, de 15 de junho de 2014. Aprova o Plano Nacional de Educação - PNE e dá outras providências. Disponível em: <http://www.planalto.gov.br/ccivil_03/_ Ato2011- 2014/Lei/L13005.htm>. Acesso em: 9 nov. 2015.

BRASIL. Lei no 11.892, de 29 de dezembro de 2008. Institui a Rede Federal de Educação Profissional, Científica e Tecnológica, cria os Institutos Federais de Educação, Ciência e Tecnologia, e dá outras providências. Disponível em: <http://www.planalto.gov.br/ ccivil_03/_ato2007-2010/2008/lei/111892.htm>. Acesso: 10 jan. 2015.

BRASIL. Lei n ${ }^{\circ} 11.096$, de 13 de janeiro de 2005. Institui o Programa Universidade para Todos - PROUNI, regula a atuação de entidades beneficentes de assistência social no ensino superior; altera a Lei nº 10.891, de 9 de julho de 2004, e dá outras providências. Diário Oficial 
[da República Federativa do Brasil], Brasília, DF, 14 jan. 2005. Disponivel em: <http://www. planalto.gov.br/ccivil_03/_ato2004-2006/2005/Lei/L11096.htm>. Acesso em: 5 jun. 2015.

BRASIL. Decreto $\mathbf{n}^{\mathbf{0}} \mathbf{5 . 2 2 4}$, de 01 de outubro de 2004, [2004a]. Dispõe sobre a organização dos Centros Federais de Educação Tecnológica e dá outras providências. Disponível em: <http://www.planalto.gov.br/ccivil_03/_ato2004-2006/2004/decreto/d5224.htm>. Acesso: 15 fev. 2016.

BRASIL. Decreto $\mathbf{n}^{\mathbf{0}} \mathbf{5 . 1 5 4}$, de 23 de julho de 2004, [2004b]. Regulamenta o $\$ 2^{\mathrm{o}}$ do art. 36 e os arts. 39 a 41 da Lei no-9.394, de 20 de dezembro de 1996, que estabelece as diretrizes e bases da educação nacional, e dá outras providências. Disponível em: $<$ http://www.planalto. gov.br/ccivil_03/_ato2004-2006/2004/decreto/d5154.htm>. Acesso: 10 dez. 2015.

BRASIL. Lei n ${ }^{\circ}$ 10.260, de 12 de julho de 2001. Dispõe sobre o Fundo de Financiamento ao Estudante de Ensino Superior - FIES. Diário Oficial da União, Brasília, 13 jul. 2001. Disponível em: <http://www.planalto.gov.br/ccivil_03/Leis/LEIS_2001/L10260.htm>. Acesso em: 20 maio 2015.

BRASIL. Lei Complementar $\mathbf{n}^{\mathbf{0}}$ 101, de 4 de maio de 2000. Estabelece normas de finanças públicas voltadas para a responsabilidade na gestão fiscal e dá outras providências. Disponível em: < http://www.planalto.gov.br/ccivil_03/leis/LCP/Lcp101.htm>. Acesso em: 24 fev. 2016.

BRASIL. Lei $\mathbf{n}^{\circ}$ 8.436, de 25 de junho de 1992. Institucionaliza o Programa de Crédito Educativo para estudantes carentes. Disponível em: < http://www.planalto.gov.br/ccivil_03/ leis/L8436.htm>. Acesso em: 24 fev. 2016.

BRASIL. Constituição (1988). Constituição da República Federativa do Brasil. Aprovada em 5 de outubro de 1988. Disponível em: < http://www.planalto.gov.br/ ccivil_03/constituicao/ConstituicaoCompilado.htm>. Acesso em: 15 fev. 2016.

BRUNO, M. et al. Finance-led growth regime no Brasil: estatuto teórico, evidências empíricas e consequências macroeconômicas. Brasília: Instituto de Pesquisa Econômica Aplicada (IPEA), dez. 2009. (Texto para Discussão n. 1455). Disponível em: <http://www. ipea.gov.br/portal/images/stories/PDFs/TDs/td_1455.pdf>. Acesso em: 10 dez. 2014.

CARVALHO, C. H. A. O ProUni no governo LULA e o jogo político em torno do acesso ao ensino superior. Educação \& Sociedade, Campinas, v. 27, n. 96 - Especial, p. 979-1000, out. 2006.

CHAVES, V. L. J. Expansão da privatização/mercantilização do ensino superior brasileiro: a formação dos oligopólios. Educação \& Sociedade, Campinas, v. 31, n. 111, p.481-500, abr-jun/2010. Disponível em <http://www.scielo.br/pdf/es/v31n111/v31n111a10.pdf>. Acesso em: 10 dez. 2014

CHAVES, V. L. J; AMARAL, N. C. A educação superior no Brasil: os desafios da expansão e do financiamento e comparações com outros países. Revista Educação em Questão, Natal (RN), v. 51, n. 37, p. 95-120, jan./abr. 2015.

CHESNAIS, F. A mundialização do capital. Tradução de Silvana Finzi Foá. São Paulo: Xamã, 1996.

COGgiolA, O. A crise do capitalismo mundial: de Nova York a Pequin, com escala em Atenas. Porto Alegre: Pradense, 2011.

COORDENAÇÃO DE APERFEIÇOAMENTO DE PESSOAL DE NÍVEL SUPERIOR (CAPES). Geocapes: dados estatísticos, 2016. [Documentos eletrônicos]. Brasília: CAPES. Disponível em: <http://www.capes.gov.br/component/content/article/91-conteudoestatico/avaliacao-capes/6886-geocapes>. Acesso em: 20 fev. 2016.

FONSECA, D. M. O pensamento privatista em educação. Campinas: Papirus, 1992. 223p. 
GUTTMANN, R. Uma introdução ao capitalismo dirigido pelas finanças. Novos Estudos, São Paulo, n. 82, p. 11-33, nov. 2008.

HARVEY, D. O enigma do capital e as crises do capitalismo. Tradução de João Alexandre Peschanski. São Paulo: Boitempo, 2011.

HELENE, O. A privatização do ensino superior. Brasil de Fato, [S.l.], n.441, 16 ago. 2011. Disponível em: <http://www.brasildefato.com.br/node/7136>. Acesso em: 19 nov. 2015.

INSTITUTO BRASILEIRO DE GEOGRAFIA E ESTATÍSTICA (IBGE). Pesquisa Nacional por Amostra de Domicílio - 2014. [Documento eletrônico]. Rio de Janeiro: IBGE. Disponível em: <www.ibge.gov.br/home/estatistica/populacao/trabalhoerendimento/ pnad2014/default.shtm>. Acesso em: 20 jan. 2016.

INSTITUTO NACIONAL DE ESTUDOS E PESQUISAS EDUCACIONAIS ANÍSIO TEIXEIRA (INEP). Sinopses estatísticas do Censo da Educação Superior: 1995; 2002; 2003; 2010; 2014. [Documentos eletrônicos]. Brasília: Inep: MEC. Disponível em: < http:// www.inep.gov.br/superior/censosuperior/sinopse/ default.asp>. Acesso em: 20 jan. 2015.

LEHER, R. Projetos e modelos de autonomia e privatizações das universidades públicas. In: GENTILI, P. (Org.). Universidades na penumbra: neoliberalismo e reestruturação universitária. São Paulo: Cortez, 2001. p. 151-187.

MARTINS, C. B. A reforma universitária de 1968 e a abertura para o ensino superior privado no Brasil. Educação \& Sociedade, Campinas, v. 30, n. 106, p. 15-35, jan./abr. 2009. Disponível em: <http://www.scielo.br/pdf/es/v30n106/v30n106a02>. Acesso: 15 jan. 2016. MARX, Karl. O Capital: crítica da economia política, livro primeiro: o processo de produção do capital. São Paulo: Ed. Nova Cultural Ltda, 1996.

MENDES, M. J. A despesa federal em Educação: 2004-2014. Boletim Legislativo, Brasília, n. 26, [boletim eletrônico], abr. 2015. Disponível em: < https://www12.senado.leg.br/publicacoes/ estudos-legislativos/tipos-de-estudos/boletins-legislativos/bol26>. Acesso em: 26 fev. 2016.

OLIVEIRA, R. P. A transformação da educação em mercadoria no Brasil. Educação \& Sociedade, Campinas, v. 30, n. 108, p. 739-760, out. 2009.

PAULANI, L. O projeto neoliberal para a sociedade brasileira: sua dinâmica e seus impasses. In: LIMA, J. C. F.; NEVES, L. M. W. Fundamentos da educação escolar do Brasil contemporâneo. 2. reimp. Rio de Janeiro: Editora FIOCRUZ, 2008. p. 67-107. Disponível em: <http://www.epsjv.fiocruz.br/upload/d/CAPITULO_2.pdf>. Acesso em: 26 fev. 2013. SGUISSARDI, V. Modelo de expansão da educação superior no Brasil: predomínio privadomercantil e desafios para a regulação e a formação universitária. Educação \& Sociedade, Campinas, SP, v. 29, n. 105, dez. 2008. Disponível em <http://www.scielo.br/pdf/es/ v29n105/v29n105a04.pdf>. Acesso em: 10 mar. 2015.

SILVA, M. A. Intervenção e consentimento: a política educacional do Banco Mundial. Campinas: Autores Associados; São Paulo: FAPESP, 2002.

VALE, A. A. A expansão do segmento privado-mercantil na educação superior brasileira: o caso da Estácio de Sá. In: CHAVES, V. J.; SILVA JÚNIOR, J. dos R.; CATANI, A. M. (Org.). A universidade brasileira e o PNE: instrumentalização e mercantilização educacionais. São Paulo: Xamã, 2013. p. 113-130.

VALE, A. A. do; CHAVES, V. J.; CARVALHO, C. H. de A. Estratégias de expansão do segmento privado-mercantil do ensino superior brasileiro e suas repercussões no trabalho docente. CONGRESSO DE BRASILEIRO DE SOCIOLOGIA, 16. 2013, Salvador (BA). Anais... Porto Alegre (RS): Soc. Bras. Sociologia; Salvador (BA): UFBA, 2013. 


\section{NOTAS}

${ }^{1} \mathrm{O}$ Consenso de Washington foi estabelecido numa reunião realizada, em novembro de 1989, em Washington, por funcionários do Departamento do Tesouro dos Estados Unidos e do Fundo Monetário Internacional (FMI), do Banco Mundial (BM) e do Banco Interamericano de Desenvolvimento (BID), que definiram medidas de ajuste fiscal nas economias capitalistas, em especial para a América Latina, e deram a direção para as reformas estruturais feitas nos países, desde então. Sobre esse assunto ver: SILVA, 2002.

${ }^{2}$ Autores de diversas correntes teóricas investigaram a financeirização e o regime de acumulação dominado pelas finanças. No Brasil, a interpretação pioneira pertence a Braga (2000). Para um mapeamento dessas abordagens, consultar: Bruno et al. (2009).

${ }^{3}$ Chesnais (1996) utiliza a expressão "capital fictício" para referir-se a um tipo de capital financeiro que se constitui com base no crescimento de ativos com valor fictício. Guttmann (2008, p. 23) esclarece que valor fictício se compõe de "créditos envolvendo compromissos de caixa futuros (títulos), cujo valor é determinado unicamente pela capitalização do rendimento previsto, sem contrapartida direta em capital produtivo [...]". Como fontes principais de capital fictício, Marx (1996, p. 77) identificou os "fundos próprios (ações) cotados na bolsa, os títulos da dívida pública e a moeda de crédito propriamente dita".

${ }^{4}$ Superávit primário representa a economia feita com as contas públicas, demonstrando a capacidade de reduzir gastos e, assim, garantir o pagamento da dívida pública junto aos credores.

${ }^{5}$ A Parceria Público Privada (PPP) foi instituída por meio da Lei no 11.079/2004.

${ }^{6}$ Em estudos anteriores, observou-se que, mesmo durante a execução do Programa de Apoio a Planos de Reestruturação e Expansão das Universidades Federais (Reuni), o acréscimo de recursos para a expansão da educação superior pública federal não foi suficiente para reduzir a distância entre o número de estudantes nela matriculados em relação ao ensino privado, uma vez que esse tem se expandido, ao longo dos anos, em proporção superior (CHAVES; AMARAL, 2015).

${ }^{7}$ Os Institutos Federais, criados pela Lei no 11.892/2008 (BRASIL, 2008), são oriundos da transformação dos Centros Federais de Educação Tecnológica (CEFET), cuja criação decorreu de regulamentação da LDB, por meio do Decreto n $^{\circ} 2.208$, de 17 de abril de 1997, que foi revogado pelo Decreto no 5.154, de 23 de julho de 2004 (BRASIL, 2004b). Os Centros Federais de Educação Tecnológica, por sua vez, originaram-se da transformação das Escolas Técnicas Federais (que, desde 1993, tornaram-se autarquias federais, conforme previu a Lei $\left.\mathrm{n}^{\circ} 8.731 / 1993\right)$. Outro marco legal de criação dos CEFETs foi o Decreto $\mathrm{n}^{\circ}$ 5.224, de $1^{\circ}$ de outubro de 2004 (BRASIL, 2004a).

${ }^{8}$ Sobre esse assunto, ver: CHAVES (2010); VALE; CHAVES; CARVALHO (2013); OLIVEIRA (2009); SGUISSARDI (2008); VALE (2013).

Submetido: 04/04/2016

Aprovado: 11/08/2016

Contato:

Vera Lúcia Jacob Chaves

Avenida Governador José Malcher, no 1913, Apto 502

Ed. Dr. Antonio Laureano Diniz

Belém | PA | Brasil

CEP 66.060-232 